\title{
Glycogene expression profiles from a HaCaT cell line stably transfected with HPV16 E5 oncogene
}

\author{
DENISSE CISNEROS-RAMÍREZ ${ }^{1,2}$, YGNACIO MARTÍNEZ-LAGUNA ${ }^{3}$, PATRICIA MARTÍNEZ-MORALES ${ }^{4}$, \\ ADRIANA AGUILAR-LEMARROY ${ }^{5}$, LUIS FELIPE JAVE-SUÁREZ ${ }^{5}$, GERARDO SANTOS-LÓPEZ ${ }^{1}$, \\ JULIO REYES-LEYVA ${ }^{1}$ and VERÓNICA VALLEJO-RUIZ ${ }^{1}$ \\ ${ }^{1}$ Laboratory of Molecular Biology, East Biomedical Research Center, Mexican Institute of Social Security, Metepec 74360; \\ ${ }^{2}$ Graduate Program in Microbiological Sciences, Institute of Sciences; ${ }^{3}$ Research Center of Microbiological Sciences, \\ Institute of Sciences, Meritorious Autonomous University of Puebla, Puebla 72592; \\ ${ }^{4}$ Consejo Nacional de Ciencia y Tecnología-Centro de Investigación Biomédica de Oriente, Metepec 74360; \\ ${ }^{5}$ West Biomedical Research Center, Mexican Institute of Social Security, Guadalajara 44290, Mexico
}

Received July 15, 2020; Accepted September 29, 2020

DOI: $10.3892 / \mathrm{mmr} .2020 .11630$

\begin{abstract}
The altered expression of glycan antigens has been reported during cervix transformation, demonstrating increased mRNA levels of certain glycogenes. Human papillomavirus (HPV) is the aetiological agent of cervical cancer. High risk HPV E5 is considered an oncogene and has been implicated in cell transformation. E6 and E7 HPV oncoproteins modify the expression of certain glycogenes. The role of the E5 HPV protein in glycogene expression changes has not yet been reported. The aim of the present study was to determine the effects of HPV16 E5 oncoprotein on glycogene expression. For these, a microarray assay was performed using the $\mathrm{HaCaT}$ cell line and altered glycogenes were identified. The mRNA levels of certain glycogenes were determined via reverse transcription-quantitative PCR (RT-qPCR). Using in silico analysis, the present study identified that glycosylation pathways were altered by E5. Microarray analysis revealed alterations in certain glycogenes, including the upregulation of ST6GAL1, ST3GAL3, CHST2 and MANBA, and the downregulation of UGT2B15, GALNT11, NDST2 and UGT1A10. Increased mRNA levels were confirmed via RT-qPCR for sialyltransferases genes. Additionally, in silico analysis was performed to identify glycosylation networks altered in the presence of the E5 oncoprotein. The analysis revealed that E5 could modify glycan sialylation, the $N$-glycosylation pathway, keratan sulfate and glycosaminoglycan synthesis. To the best
\end{abstract}

Correspondence to: Dr Verónica Vallejo-Ruiz, Laboratory of Molecular Biology, East Biomedical Research Center, Mexican Institute of Social Security, Km 4.5 Carretera Federal, s/n AtlixcoMetepec, Metepec 74360, Mexico

E-mail: veronica_vallejo@yahoo.com

Key words: human papillomavirus 16, E5 oncoprotein, human papillomavirus, glycogene, glycosylation, microarray expression of our knowledge, the current study was the first to determine the role of the HPV16 E5 oncoprotein in glycogene expression changes. The results indicated that increased sialyltransferase mRNA levels reported in pre-malignant and malignant cervical tissues could be the result of E5 oncoprotein expression. The results provide a possible role of HPV infection on glycosylation changes reported during cervix transformation.

\section{Introduction}

Human papillomavirus (HPV) is the aetiological agent of cervical cancer (CC) (1). HPV16 is the most prevalent genotype and is responsible for greater than $50 \%$ of $\mathrm{CC}$ cases worldwide $(2,3)$. The oncogenic potential of HPV is attributed to the following three viral proteins: E5, E6 and E7. E6 and E7, the best characterized viral proteins, promote cell transformation by several mechanisms; for example, they destabilize and induce the degradation of the tumour suppressor proteins $\mathrm{p} 53$ and pRB, respectively (4). Meanwhile, E5, a transmembrane protein present in the Golgi apparatus, endoplasmic reticulum and nuclear envelope (5), has several roles in cell transformation. For example, E5 can force cells through the cell cycle and promote the evasion of the immune response (6). Additionally, E5 can modify gene expression; HPV16 E5 induces the expression of prostaglandin E2 receptor by stimulating the binding of the cAMP-response element binding protein (CREB) to its promoter, which activates mitogenic activated protein kinase (MAPK) and increases $C$-FOS and $C$-JUN transcription $(7,8)$. Moreover, E5 increases the expression of genes related to cell adhesion, cell motility, and mitogenic signalling, suggesting that the protein plays an important role in the events associated with cellular transformation (9).

Altered glycosylation is another characteristic of cancer cells (10), and it can be caused by the altered expression of different glycosyltransferases that can lead to changes in glycan structures. Increased mRNA levels of some sialyltransferases have been reported in different cancer types (11). Specifically, $\mathrm{CC}$ and premalignant lesions display increased $\mathrm{mRNA}$ levels of 
the sialyltransferases ST3GAL3 and ST6GAL1 $(12,13)$, which are related to increased expression of sialic acid $(14,15)$ and of sialylated antigens such as sTn and SLe(x) (16-18). Studies in the HeLa cell line show that E6/E7 HPV18 oncogene knockdown modified glycogene expression, some of which participate in the synthesis of $O$-glycans such as sTn (19). These results suggest that viral infection could modify glycogene expression and the glycosylation of the cervical epithelium.

The objective of this work was to identify glycogenes that displayed modified expression patterns in the presence of the HPV16 E5 oncoprotein. The results showed that the HPV16 E5 oncoprotein could increase the expression of the sialyltransferases $S T 3 G A L 3$ and $S T 6 G A L 1$, which have been reported to be altered in premalignant and malignant cervical tissues. The network interaction constructed with the altered glycogenes in the presence of E5 showed that not only the glycan sialylation but also some glycan structures, such keratan sulphate and glycosaminoglycans, could also be altered.

\section{Materials and methods}

Cell culture. The HaCaT cell line from human skin keratinocytes stably transfected with the HPV16 E5 oncogene (HaCaT-E5) (20) or the vector pMSG (HaCaT-pMSG) (kindly donated by Dr. A. Alonso from German Cancer Research Centre, University of Heidelberg, Germany) was cultured and maintained in Dulbecco's modified Eagle's medium (DMEM) containing Earle's salts and L-glutamine (DMEM; Sigma-Aldrich; Merck KGaA) and supplemented with $10 \%$ foetal bovine serum (Biowest), $100 \mu \mathrm{g} / \mathrm{ml}$ streptomycin (Sigma-Aldrich; Merck KGaA). The CasKi cell line from a squamous CC (kindly donated by Dr A. Aguilar-Lemarroy from Centro de Investigación Biomédica de Occidente, IMSS) was cultured and maintained in RPMI-1640 medium (Sigma-Aldrich; Merck KGaA) containing L-glutamine and supplemented with $10 \%$ foetal bovine serum, and $100 \mu \mathrm{g} / \mathrm{ml}$ streptomycin (Sigma-Aldrich; Merck KGaA). Cells were maintained at $37^{\circ} \mathrm{C}$ with an atmosphere of $5 \% \mathrm{CO}_{2}$. The culture medium was replaced every two days. Sub-confluent cells were harvested using a mixture of trypsin $(0.025 \%)$ and EDTA (0.02\%; Sigma-Aldrich; Merck KGaA) and were washed with phosphate-buffered saline.

Microarray expression assay. The microarray expression assay was performed at the Cellular Physiology Institute of UNAM. The microarray contained 10,000 gene-specific oligonucleotide probes representing the best-annotated genes from human. For the probe preparation, total RNA from HaCaT/E5 and HaCaT/pGSM monocultures was obtained with the ReliaPrep ${ }^{\mathrm{TM}}$ RNA Cell Miniprep System (Promega Corporation) and $10 \mu \mathrm{g}$ of each RNA was used for cDNA synthesis incorporating dUTP-Alexa555 or dUTP-Alexa647 and employing the First-Strand cDNA labelling kit (Invitrogen; Thermo Fisher Scientific, Inc.). Acquisition and quantification of the array images were performed in GenePix 4100A with its accompanying software GenePix from Molecular Devices. Microarray data analysis was performed with the free software GenArise developed at the Computing Unit of Cellular Physiology Institute of UNAM (http://www.ifc. unam.mx/genarise/). The software identifies differentially expressed genes by calculating an intensity-dependent z-score. The elements with a $\mathrm{z}$-score $>2$ standard deviations would be the significantly differentially expressed genes. The analysed data were submitted to the NCBI Gene Expression Omnibus (access no. GSE118776).

Expression analysis of E5 and glycogenes. Total RNA from CasKi, HaCaT-E5 and HaCaT-pMSG monocultures was obtained with the NucleoSpin II RNA kit (Macherey-Nagel).

To determine the amplification efficiencies of E5, ST3GAL3 and ST6GAL1, standard curves were performed with the following RNA concentrations: $10,1,0.1,0.01$, and $0.001 \mathrm{ng} / \mu \mathrm{l}$. HPRT was used as an endogenous gene. Based on these curves we determined the better concentration to perform the relative quantification assays, considering that these genes have different expression levels. cDNA was synthesized using random primers and the RevertAid First-Strand cDNA Synthesis kit (Thermo Fisher Scientific, Inc.). qPCR reactions were performed in a final volume of $10 \mu \mathrm{l}$ with the following components: $5 \mu \mathrm{l}$ of 2X Maxima SYBR-Green/Rox qPCR Master Mix (Thermo Fisher Scientific, Inc.) and $0.5 \mu \mathrm{l}$ of $10 \mathrm{mM}$ forward and reverse primers (Table I). The reactions were performed with a StepOne Real-Time PCR System (Applied Biosystems; Thermo Fisher Scientific, Inc.), and the cycling conditions were as follows: $95^{\circ} \mathrm{C}$ for $10 \mathrm{~min}$, followed by 40 cycles of $95^{\circ} \mathrm{C}$ for $30 \mathrm{sec}$, an annealing temperature for $30 \mathrm{sec}$, and $70^{\circ} \mathrm{C}$ for $30 \mathrm{sec}$. For HPV16 E5, the Tms for HPV16 E5, ST3GAL3 and ST6GAL1 were $55^{\circ} \mathrm{C}, 57^{\circ} \mathrm{C}$ and $60^{\circ} \mathrm{C}$, respectively.

Relative quantification was performed using the comparative CT method as follows: $2^{-\Delta \Delta C T}$. The qPCR reaction was performed on a StepOne Real-Time PCR System (Applied Biosystems; Thermo Fisher Scientific, Inc.). The final $10 \mu \mathrm{l}$ reaction volume included $1 \mu \mathrm{l}$ of cDNA template (E5 VPH16-0.5 ng/ $\mu \mathrm{l}$; ST3GAL3-10 $\mathrm{ng} / \mu \mathrm{l}$, or ST6GAL1-3 ng/ $\mu 1$ ), $5 \mu$ l of $2 \mathrm{X}$ Maxima SYBR-Green/Rox qPCR Master Mix (Thermo Fisher Scientific, Inc.), $0.5 \mu 1$ of forward and reverse primers $(0.5 \mu \mathrm{M}$ final concentration) and $3 \mu 1$ of RNase free water. qPCR was performed under with following conditions: $95^{\circ} \mathrm{C} 10 \mathrm{~min}$, followed 40 cycles of $95^{\circ} \mathrm{C}$ for $30 \mathrm{sec}$, the annealing temperature for $30 \mathrm{sec}\left(60^{\circ} \mathrm{C}\right.$ for ST6GAL1 and $57^{\circ} \mathrm{C}$ for ST3GAL3) and $70^{\circ} \mathrm{C}$ for $30 \mathrm{sec}$. The gene transcript levels were analysed and normalised to HPRT expression.

Identification of glycogenes. For the analysis of the glycogenes in the microarray displaying altered expression, we considered 336 glycogenes reported to date using the GlycoGene database (http://riodb.ibase.aist.go.jp/rcmg/ggdb/), the Consortium for Functional Glycomics-CAZy database (http://www. cazy.org/CAZY/) and the published reports on glycogenes not included in the databases, including DPY19L1 (21) and $M A N B A L$ (22). We identified glycogenes displaying altered expression in the microarray as those with a z-score $>2$.

Protein-protein interaction network. The downregulated or upregulated set of glycogenes in the HaCaT-E5 cells were submitted separately, to the STRING database (http://string-db. org/). The following parameter were applied for the analysis: text mining, experiments, databases, co-expression, 
Table I. Sequences of the oligonucleotides used in the reverse transcription-quantitative PCR assays.

\begin{tabular}{lllc}
\hline Primer & \multicolumn{1}{c}{ Forward (5'-3') } & \multicolumn{1}{c}{ Reverse (5'-3') } & $\begin{array}{c}\text { Length (bp) } \\
\text { Product }\end{array}$ \\
\hline HPRT & CCTGGCGTCGTGATTAGTGATGAT & CGAGCAAGACGTTCAGTCCTGTC & 150 \\
HPV16 E5 & CGCTGCTTTTGTCTGTTCT & GCGTGCATGTGTATGTATTAAAAA & 146 \\
ST3GAL3 & CATGTGAAGATGGGACTCTTGG & CCTCCCACTGGAGTAAGTGTAG & 118 \\
ST6GAL1 & TATCGTAAGCTGCACCCCAATC & TTAGCAGTGAATGGTCCGGAAG & 372 \\
\hline
\end{tabular}

HPRT, hypoxanthine-guanine phosphoribosyltransferase; HPV, human papilloma virus; ST3GAL3, ST3 $\beta$-galactoside $\alpha$-2,3-sialyltransferase 3 ; ST6GAL1, $\beta$-galactoside $\alpha$-2,6-sialyltransferase 1 ; bp, base pair.

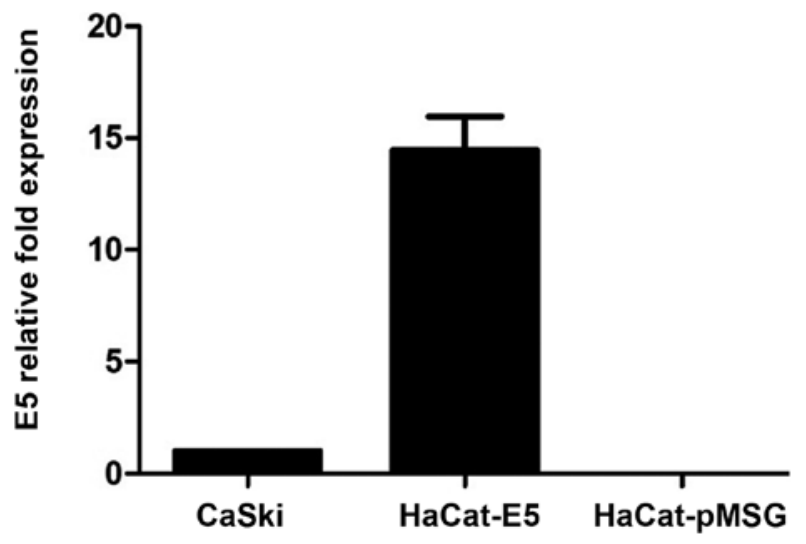

Figure 1. Human papillomavirus-16 E5 mRNA expression. E5 mRNA expression was 14.4 times higher in HaCaT-E5 cells compared with CasKi cells. HaCaT-pMSG was used as a negative control. Data are presented as the mean $\pm \operatorname{SEM}(n=3)$.

neighbourhood, gene fusion and co-occurrence as interaction sources, no more than 5 interactor, minimum interaction score of 0.9 as confidence level, and a protein-protein enrichment P-value at least $\leq 0.05$ and FDR at least $<0.05$.

Statistical analysis. Statistical analysis of the qPCR results was performed using the GraphPad program. The Student's t-test was performed. A P-value $<0.05$ was considered statistically significant.

\section{Results}

E5 oncogene expression by $R T-q P C R$. RT-qPCR was performed to quantify E5 mRNA expression levels from HaCaT-E5 cells, as a positive control it was used mRNA of CasKi cells (a cell line that contains HPV16-integrated genomes and expresses E5) and as a negative control was used mRNA of HaCaT-pMSG. Fig. 1 shows the relative expression of E5, showing that E5 expression is greater in HaCaT-E5 than in CasKi cells.

Glycogene expression altered by the E5 oncoprotein. From a total of 336 glycogenes reported to date, we searched those altered in the HaCaT-E5 microarray with respect to HaCaT-pGSM. We identified four upregulated glycogenes, including ST3GAL3, CHST2 and MANBA with a z-score $>2$ and $S T 6 G A L 1$ with a $\mathrm{z}$-score of 1.8 . The latter was included because of its importance in CC. We also identified four downregulated glycogenes, including GALNT11, NDST2, UGT2B15 and $U G T 1 A 10$ with a z-score $<2$. The microarray data analysed herein are included in the NCBI Gene Expression Omnibus Database (accession no. GSE118776) and in the article text.

E5 increased the expression of the sialyltransferases ST3GAL3 and ST6GAL1. Because the microarray results showed that the presence of E5 can lead to an increase in sialyltransferases expression, we evaluated the mRNA levels of STBGAL3 and ST6GAL1 by RT-qPCR in HaCaT-E5 and HaCaT-pMSG cells. ST3GAL3 and ST6GAL1 mRNA levels were increased in HaCaT-E5 cells (Fig. 2).

We next analysed literature data for E5-modified glycogenes that also have been previously reported as altered in cancerous tissues [Tables II and III; $(11,12,22-45)]$. First, we analysed the upregulated genes. As previously described, ST3GAL3 and ST6GAL1 were increased in CC and premalignant lesions; in contrast, CHST2 and MANBA have not been reported in $\mathrm{CC}$, but display altered expression in other cancer types. The results showed that the four glycogenes are aberrantly expressed in several types of cancer and have clinical relevance (Table II).

We next compared the downregulated glycogenes in HaCaT-E5 cells with those reported in cancerous tissues. The four glycogenes have been reported in cancer. GALNT11 is overexpressed in chronic lymphocytic leukaemia (CLL), and UGT2B15 is downregulated in prostate cancer, but none of the downregulated glycogenes have been previously reported to be altered in CC (Table III).

E5 and glycosylation pathways. To identify possible functional associations among the enzymes identified as altered glycogenes under E5 regulation, we analysed the data with STRING software to generate predicted protein-protein interactions with a higher confidence level (0.9). For the analysis, we considered the altered glycogenes and five additional proteins with the goal of identifying possible glycosylation pathways.

For the upregulated glycogenes (ST3GAL3, CHST2, $M A N B A$ and $S T 6 G A L 1$ ), the results displayed an interacting network with eight proteins where MANBA did not interact with any protein but participates in $N$-glycosylation (Fig. 3A). Specifically, we identified the keratan sulfate biosynthesis pathway, which includes CHST2 and ST3GAL3 (Fig. 3B); the $N$-glycosylation pathway, in which both the sialyltransferase genes are involved in the sialylation of $N$-glycans (Fig. 3C); and 
A

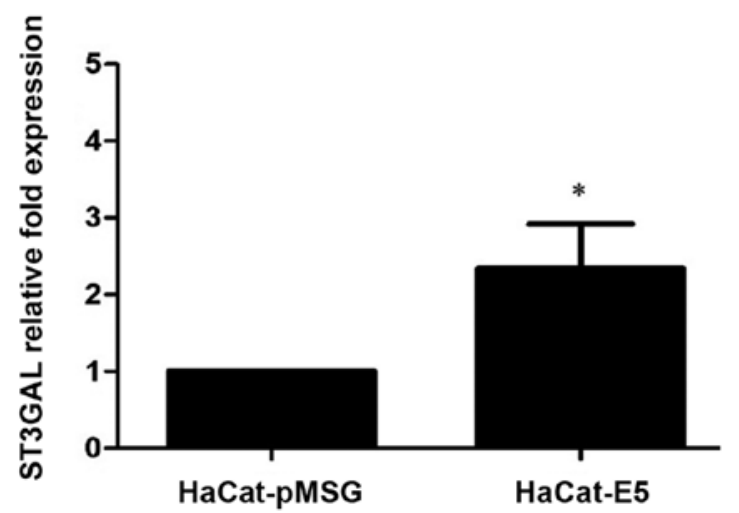

B

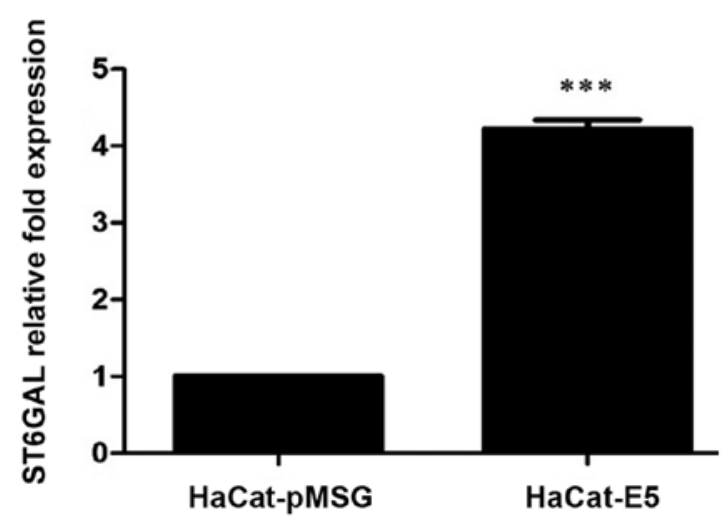

Figure 2. Expression levels of sialyltransferases genes. (A) mRNA levels of ST3GAL3 in HaCaT-pMSG and HaCaT-E5 cells determined by RT-qPCR. (B) mRNA levels of ST6GAL1 in HaCaT-pMSG and HaCaT-E5 cells determined by RT-qPCR. The mRNA levels of sialyltransferases genes were increased in presence of E5. Data are presented as the mean $\pm \mathrm{SD}$ of three independent experiments performed in triplicate assays. ${ }^{*} \mathrm{P}<0.05$ and ${ }^{* * *} \mathrm{P}<0.001$. $\mathrm{RT}-\mathrm{qPCR}$, reverse transcription-quantitative PCR.

the glycosphingolipid biosynthesis pathway, where ST3GAL3 participates with fucosyltransferases and galactosyltransferases (Fig. 3D).

For the downregulated glycogenes (UGT2B15, GALNT11, NDST2 and UGT1A10), the interaction analysis showed two different networks, among which GALNT11 was excluded from the first network and NDST2 establishes a separate network (Fig. 4A). The analysis showed that the latter is involved in glycosaminoglycan biosynthesis (Fig. 4B).

\section{Discussion}

Aberrant glycosylation is a characteristic of tumour cells. Changes in glycan structures in cancer have been related with altered glycogene expression (46). Increased sialylation is one of the most frequent alterations in cancer (47). Increased activity of sialyltransferases, enzymes that transfer sialic acid to glycoconjugates, has been reported during tumour transformation $(11,48)$. Increased $\alpha 2,3$ and $\alpha 2,6$ sialic acid levels have been reported in premalignant lesions from the cervical epithelium (14). Increased expression of the sialylated antigens sLe(a) and sLe(x) have also been reported in CC and premalignant lesions $(17,18)$. These findings could be the result of enhanced ST3GAL3 and ST6GAL1 (sialyltransferase genes) mRNA levels, which have been previously reported during cervical transformation $(12,13)$. HPV is the aetiological agent of CC, and the HPV genome encodes three oncoproteins, E5, E6 and E7 (4); however, their roles in altering glycogene expression have been poorly investigated. Our research group is interested in the role of HPV infection and its relationship with glycogene expression changes in the cervical epithelium. Our group recently reported that the oncoproteins E6 and E7 from HPV18 modify the expression of some glycogenes, some of which participate in the glycosylation of the Notch receptor and $O$-glycosylation type mucin (19). However, similar reports focused on the E5 oncoprotein do not exist. E5 is a protein expressed during the early stages of viral infection, and this protein has different targets in the cell that promote cellular transformation $(6,49)$.

With the aim of determining whether E5 modifies the expression of some glycogenes, we performed an expression microarray on the HaCaT cell line stably transfected with the HPV16 E5 oncoprotein. We identified four upregulated glycogenes (CHST2, MANBA, ST3GAL3 and ST6GAL1) and four downregulated glycogenes (UGT2B15, GALNT11, NDST2 and UGT1A10). All these genes have been reported to be altered in cancer either at the transcript or protein level (Tables II and III).

Increased CHST2 mRNA levels have been reported in osteosarcoma and breast and oesophageal cancer (33-35), while increased protein levels have been reported in ovarian cancer and CC (36). With regards to the glycogene $M A N B A$, increased mRNA levels have only been reported in oesophageal cancer (37). Interestingly, of the four upregulated glycogenes, two correspond to the sialyltransferases genes ST3GAL3 and ST6GAL1. ST3GAL3 expression has been reported as altered in different cancer types, such as gastric, bile, colon, kidney, lung, breast, and ovarian cancers and glioblastoma (11,23-27). Increased ST6GAL1 mRNA and protein expression has been reported in gastric and biliary cancers $(24,27)$, colon and colorectal cancers $(25,29,31)$, and ovarian and pancreatic cancers $(11,30)$. Here, we showed that the mRNA levels of the ST6GAL1 and ST3GAL3 genes can be increased by the presence of E5; interestingly, both mRNA levels are increased in premalignant and malignant tissues in the cervical epithelium $(12,13)$. However, whether these phenotypes could be a consequence of HPV infection remains unclear. Additionally, the upregulation of these genes agrees with the increased levels of sialic acid reported for $\mathrm{CC}$ and with the increased levels of $\alpha 2,3$ and $\alpha 2,6$ sialic acid in premalignant lesions in the cervix (14). These results suggest that the sialyltransferase expression changes that occur in the early stages of cervical cell transformation could be related to HPV infection and due to E5, but not E6 or E7, activity (19). Nevertheless, this hypothesis requires more investigation. With respect to E5 and sialylation, a previous study found no important changes in the sialylation status of keratinocytes in the presence of HPV16 E5 (50), however, in this study the authors analysed the expression of different monosaccharaides and disaccharides, using a panel of seven lectins, but they did not perfom glycogene expression analysis. Additionally, as they use an inducible vector, they 


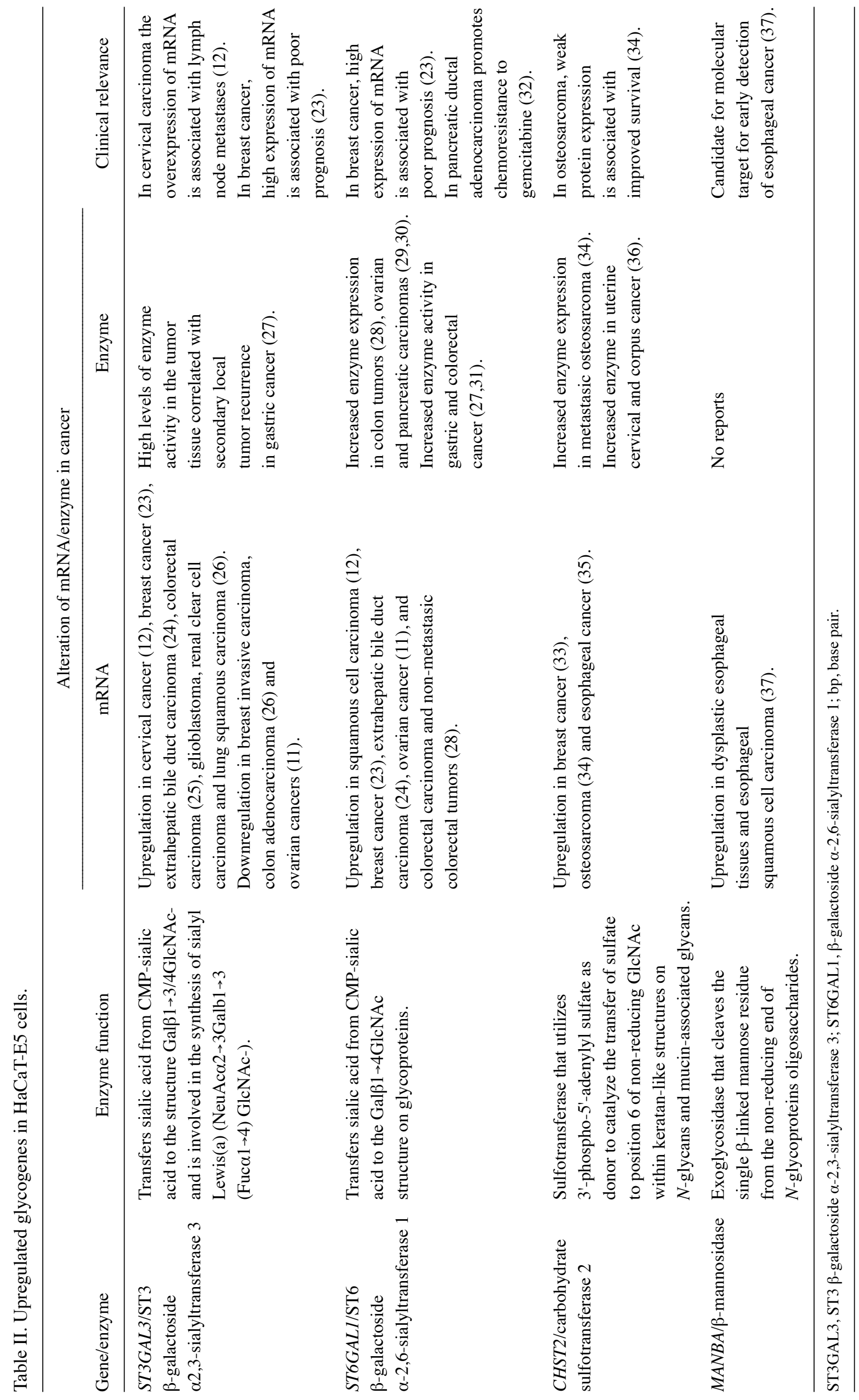




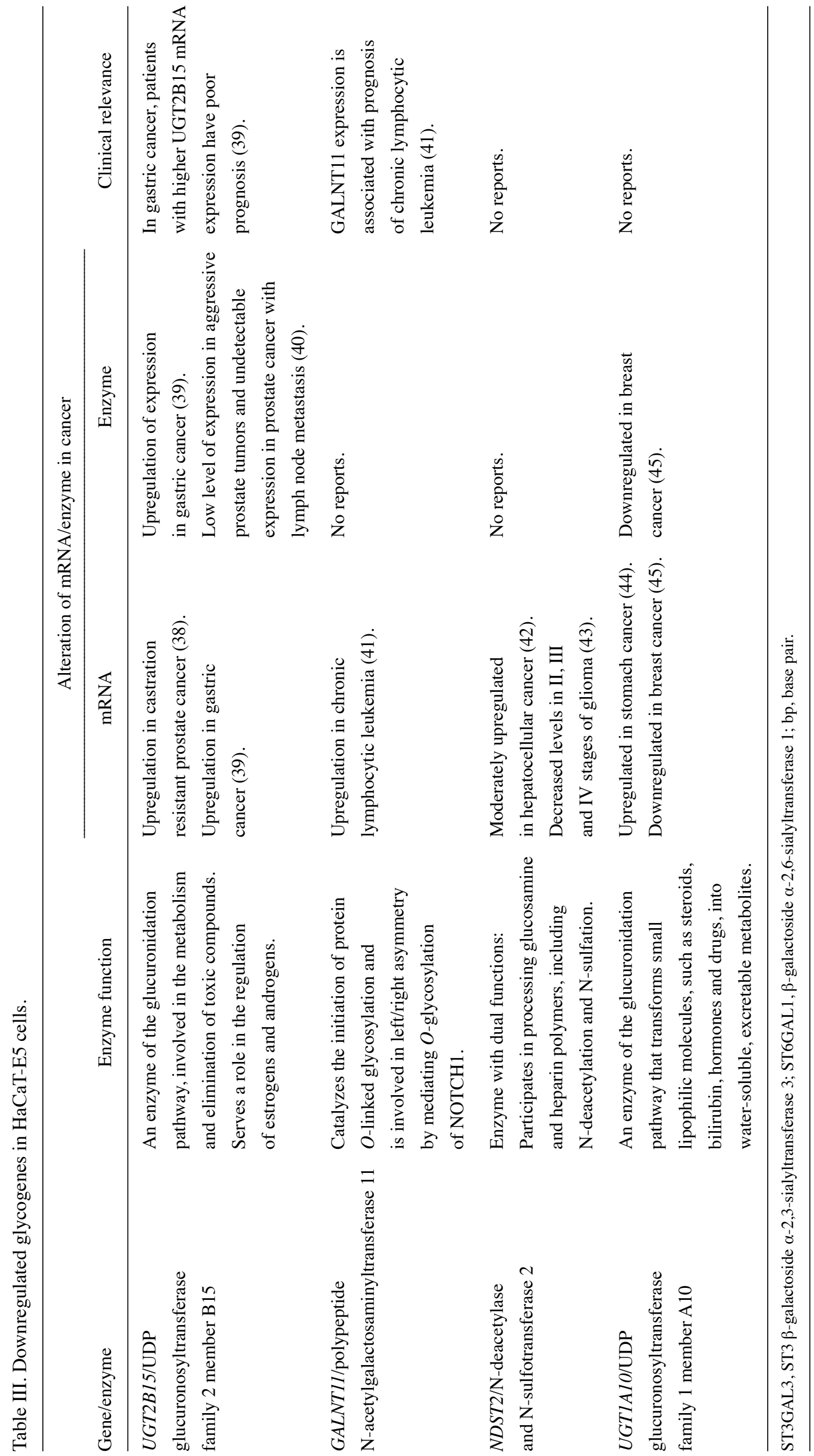



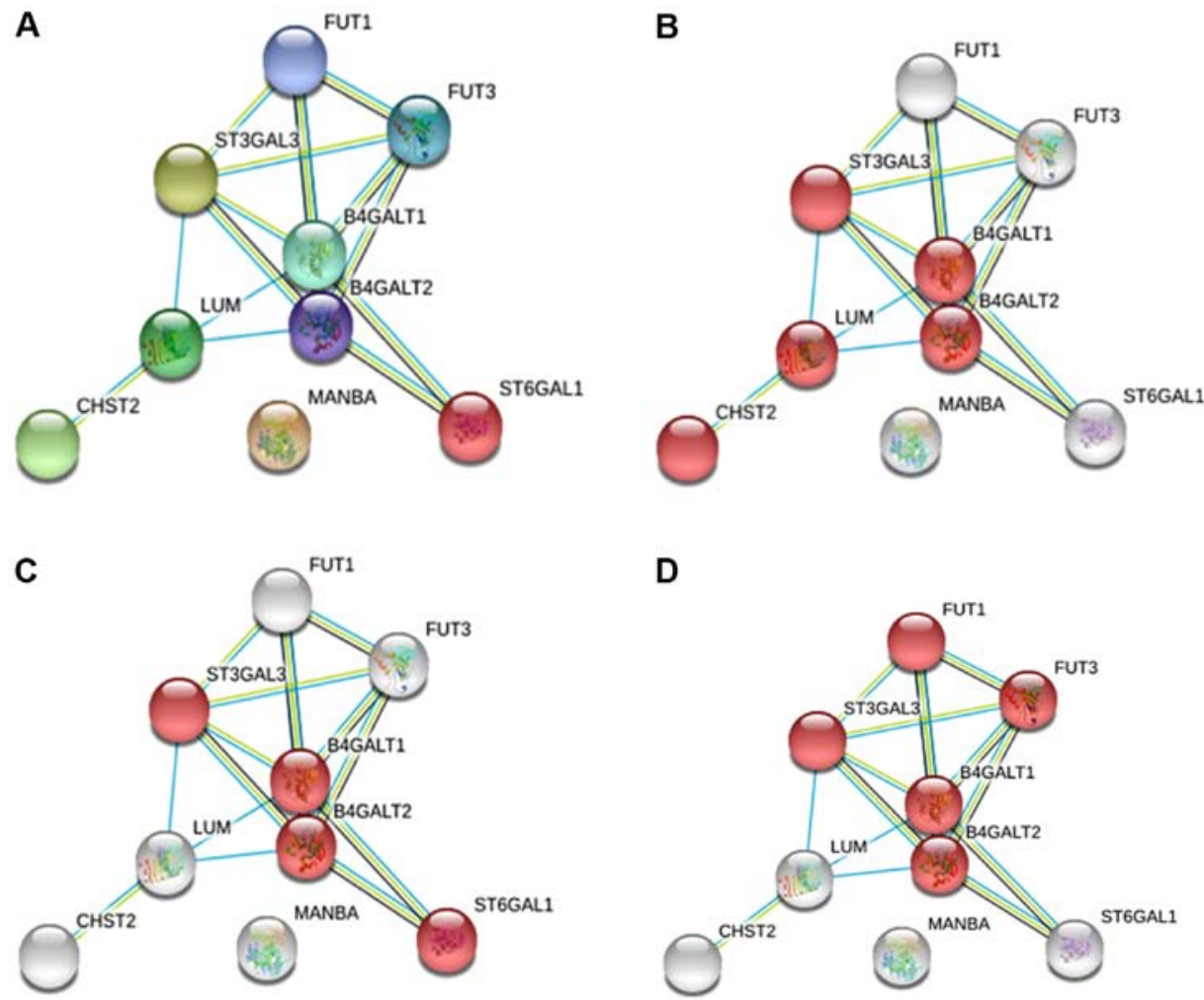

Figure 3. Protein-protein interaction network of the upregulated glycogenes. (A) Network of upregulated glycogenes with five additional proteins that interacted with the altered glycogenes. (B) The red network indicates proteins that participate in the keratan sulfate biosynthetic process. (C) The red network indicates the proteins that participate in $N$-glycosylation. (D) The red network indicates the proteins that participate in glycosphingolipid biosynthesis.

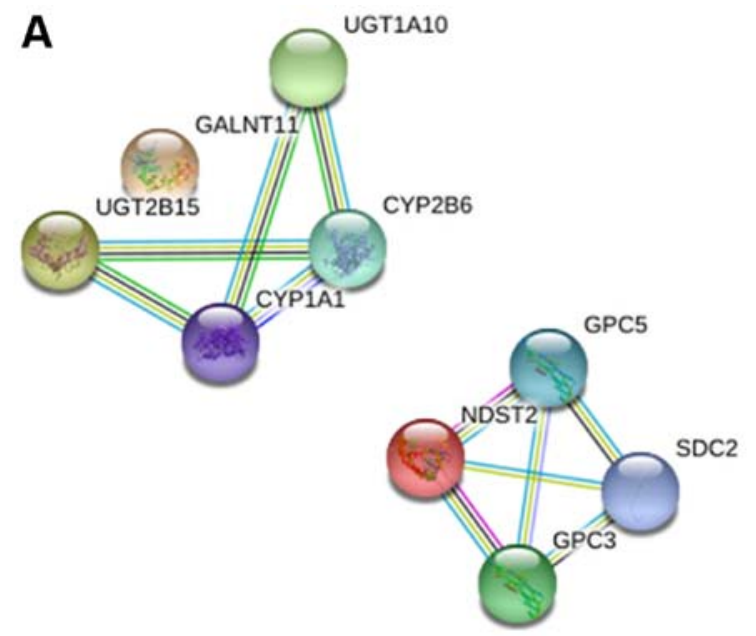

B

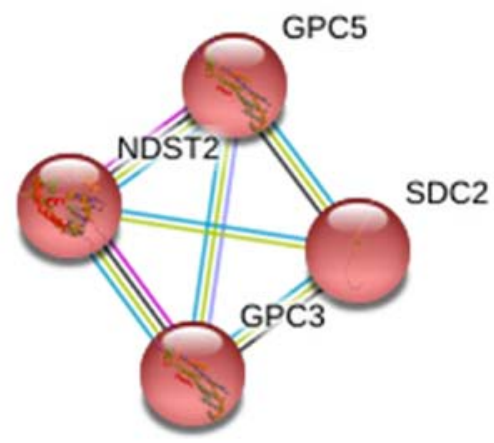

Figure 4. Protein-protein interaction network of the downregulated glycogenes. (A) Network of downregulated glycogenes including five additional proteins that interacted with the altered glycogenes. (B) The red network indicates proteins that participate in glycosaminoglycan biosynthesis.

incubated the transfected cells with dexamethasone to increase the expression of E5, so the glycosylation pattern could be influenced by the effect of this molecule, as has been reported in different studies where the dexamethasone increase the sialyltransferases expression $(51,52)$.

Regarding the downregulated genes in the presence of HPV16 E5, GALNT11 has been reported as diminished in breast cancer (33) and increased in chronic lymphocytic leukaemia, and it was proposed to be implicated in $O$-glycosylation changes in chronic lymphocytic leukaemia (CLL) cells (41). NDST2 has demonstrated increased mRNA levels in hepatocellular cancer (42). It was also interesting to find expression changes in two UGT genes (UGT2B15 and UGT1A10) that encode uridine 5'-diphospho-glucuronosyltransferases as these enzymes play important roles in the biotransformation of drugs, xenobiotics, and toxic compounds (44). Expression changes in UGT genes could modify the response to some cancer drugs. UGT2B15 has been reported as diminished in prostate cancer (40), and UGT1A10 has been reported as downregulated in breast cancer (45) but upregulated in gastric cancer (44). These $U G T$ genes have not been previously reported as altered in $\mathrm{CC}$; thus, it could be interesting to analyse their expression status and 
the response of patients to treatment when their expression is altered.

Additionally, we also identified possible glycosylation pathways altered in the presence of E5 by analysing protein-protein interactions. We identified keratan sulfate and glycosphingolipid synthesis as including the involvement of the glycogenes ST3GAL3, ST6GAL1 and CHST2. Keratan sulfate belongs to the family of glycosaminoglycans, which participates in the regulation of cellular functions in epithelial and mesenchymal tissues (53).

The glycogenes ST3GAL3 and ST6GAL1 are involved in sialylation of glycosphingolipid. These glycolipids can be located in the cellular membrane, participate in cell-cell interactions and modulate transduction pathways, cell growth, apoptosis, cell proliferation, endocytosis, cell migration, senescence and embryogenesis $(54,55)$. The aberrant expression of glycosphingolipids and the enzymes that participate in their biosynthesis has been reported in different cancer types (56). The expression of the ganglioside GM1 has been reported as being increased in ectocervix cells expressing VPH16 E5; gangliosides are expressed at high levels on tumour cells and inhibit cytotoxic T lymphocytes (56). Our results support these findings, demonstrating that E5 could be modifying ganglioside synthesis.

The glycogenes present in the $N$-glycosylation pathway are ST3GAL3 and ST6GAL1. Changes in sialic acid expression have been reported for different cancer types including $\mathrm{CC}$, as was mention previously (11). Increased expression of sialylated antigens such as SLe(x) and sLe(a) has been reported in premalignant lesions and CC, and the enzyme ST3Gal III participates in the synthesis of both of these antigens $(17,18,57)$. sLe(x) antigens can be modified by the enzyme sulfotransferase CHST2 to produce 6-sulfosialil Lewis-x (6-sulfo sLex), which can be a ligand of L-, P- and E-selectin (58). Moreover, ST6Gal I catalyses the $\alpha 2,6$ sialylation of $N$-glycans, and its expression is increased in different types of cancer (59). ST6Gal I had been implicated in the hypersialylation of the cell membrane protein $\beta 1$ integrin in tumour cells, which leads to increased migration capacity (60). ST6Gal I also participates in the sialylation of epidermal growth factor receptor (EGFR) (61), which showed increased expression due to HPV16 E5 (62).

For the downregulated genes, the network interactions implicated in a glycosylation pathway involved only one glycogene. Fig. 4 shows a network of four proteins implicated in glycosaminoglycan biosynthesis, but only one glycogene, NDST2, was present in this network. The upregulation of NDST2 has been related to an increase in heparan sulfate (63).

For the glycogenes downregulated in the presence of E5, there are no reports focused on CC; thus, it would be important to evaluate their expression and roles in cervical transformation.

The results of this study provide important information related to glycogenes that modify their expression in the presence of the HPV-16 E5 protein. The expression microarray generated large amounts of information on the genes that were altered, but the results must be validated. The study present some limitations, it is important to confirm that the expression of the gene is related with the expression level of its corresponding protein, additionally, the study was performed in a cell line, so the role of the HPV infection and the expression of the other viral proteins could be participating in the glycosylation changes, so the effect of E5 could be affected by other factors. Therefore, the results must be confirmed with more in vitro experiments, followed by the evaluation of glycogene expression in different stages in cervical neoplasias positive for HPV16, as some of the altered glycogenes have not been previously reported in premalignant and malignant tissues. Also, it could be of interest to evaluate if the protein E5 from different viral genotypes, plays a different role in the glycosylation changes. Studying the effects of E5 of high and low risks HPV, will certainly provide relevant additional information of the effects of this viral infection.

The expression of the HPV16 E5 protein in HaCaT cells increased ST3GAL3 and ST6GAL1 mRNA levels, suggesting that the E5 protein could participate in the glycosylation changes found during cervical transformation in the cervical epithelium infected with HPV, especially those related to increased $\alpha 2,3$ and $\alpha 2,6$ sialylation, which have been reported as enhanced in premalignant lesions and CC. Additionally, E5 could participate in $U G T$ gene expression changes implicated in treatment response. Changes in $U G T$ gene expression have not been previously reported; thus, it would be interesting to analyse their levels in CC samples as well as to examine the correlation of these changes with responses to treatment.

\section{Acknowledgements}

The authors would like to thank Dr Lorena Chávez González, Dr Simón Guzmán León, Dr José Luis Santillán Torres and Dr Jorge Ramírez for their technical assistance with microarray determinations. The authors would also like to thank Mr. Gerardo Coello, Mr. Gustavo Corral and Ms. Ana Patricia Gómez for their assistance with the genArise software. All the previously mentioned individuals are affiliated to the Cellular Physiology Institute of National Autonomous University of Mexico.

\section{Funding}

The current study was supported by the Consejo Nacional de Ciencia y Tecnología (grant no. SALUD-2017-01-290068). JRL has a fellowship from the Fundación IMSS (grant no. 8066205). DCR was supported by a Ph.D. fellowship from CONACYT (grant no. 242745) and IMSS (grant no. 98227564). Funding was also provided by the Programa Cátedras CONACYT 2016 (grant no. 485) and Fondo Redes Temáticas de Investigación CONACYT (grant no. 253596).

\section{Availability of data and materials}

The datasets generated and analysed during the current study are available in the repository NCBI Gene Expression Omnibus database, (accession no. GSE118776; https://www. ncbi.nlm.nih.gov/geo/query/acc.cgi?acc=GSE118776).

\section{Authors' contributions}

DCR performed molecular biology experiments, in silico analysis, data analysis and revised the manuscript. YML participated in data analysis and critically revised the manuscript. PMM participated in the in silico and data analyses, and critically revised the manuscript. AAL analysed the data and critically revised the manuscript. LFJS participated in the 
in silico analysis and critically revised the manuscript. GSL participated in the molecular biology experiments, analysed the data and revised the manuscript. JRL designed the current study, analysed the data and critically revised the manuscript. VVR conceived and designed the current study, coordinated the study and draft the manuscript. All the authors read and approved the final manuscript.

\section{Ethics approval and consent to participate}

Not applicable.

\section{Patient consent for publication}

Not applicable.

\section{Competing interests}

The authors declare that they have no competing interests.

\section{References}

1. zur Hausen H: Papillomaviruses in the causation of human cancers - a brief historical account. Virology 384: 260-265, 2009.

2. Smith JS, Lindsay L, Hoots B, Keys J, Franceschi S, Winer R and Clifford GM: Human papillomavirus type distribution in invasive cervical cancer and high-grade cervical lesions: A meta-analysis update. Int J Cancer 121: 621-632, 2007.

3. Aguilar-Lemarroy A, Vallejo-Ruiz V, Cortés-Gutiérrez EI, Salgado-Bernabé ME, Ramos-González NP, Ortega-Cervantes L, Arias-Flores R, Medina-Díaz IM, Hernández-Garza F, Santos-López G, et al; IMSS Research Network on HPV: Human papillomavirus infections in Mexican women with normal cytology, precancerous lesions, and cervical cancer: Type-specific prevalence and HPV coinfections. J Med Virol 87: 871-884, 2015.

4. Münger K and Howley PM: Human papillomavirus immortalization and transformation functions. Virus Res 89: 213-228, 2002.

5. Conrad M, Bubb VJ and Schlegel R: The human papillomavirus type 6 and 16 E5 proteins are membrane-associated proteins which associate with the 16-kilodalton pore-forming protein. J Virol 67: 6170-6178, 1993.

6. Venuti A, Paolini F, Nasir L, Corteggio A, Roperto S, Campo MS and Borzacchiello G: Papillomavirus E5: The smallest oncoprotein with many functions. Mol Cancer 10: 140, 2011.

7. Chen SL, Huang CH, Tsai TC, Lu KY and Tsao YP: The regulation mechanism of c-jun and junB by human papillomavirus type 16 E5 oncoprotein. Arch Virol 141: 791-800, 1996.

8. Chen SL, Lin YK, Li LY, Tsao YP, Lo HY, Wang WB and Tsai TC: E5 proteins of human papillomavirus types 11 and 16 transactivate the $\mathrm{c}$-fos promoter through the NF1 binding element. J Virol 70: 8558-8563, 1996.

9. Kivi N, Greco D, Auvinen P and Auvinen E: Genes involved in cell adhesion, cell motility and mitogenic signaling are altered due to HPV 16 E5 protein expression. Oncogene 27: 2532-2541, 2008.

10. Varki A, Kannagi R, Toole B and Stanley P: Glycosylation Changes in Cancer. In: Essentials of Glycobiology [Internet]. 3rd edition. Varki A, Cummings RD, Esko JD, Stanley P, Hart GW, Aebi M, Darvill AG, Kinoshita T, Packer NH, Prestegard JH, et al (eds). Cold Spring Harbor Laboratory Press, Cold Spring Harbor, NY, 2017.

11. Wang PH: Altered Glycosylation in Cancer: Sialic Acids and Sialyltransferases. J Cancer Mol 1: 73-81, 2005.

12. Wang PH, Li YF, Juang CM, Lee YR, Chao HT, Ng HT, Tsai YC and Yuan CC: Expression of sialyltransferase family members in cervix squamous cell carcinoma correlates with lymph node metastasis. Gynecol Oncol 86: 45-52, 2002.

13. López-Morales D, Velázquez-Márquez $\mathrm{N}$, Valenzuela $\mathrm{O}$, Santos-López G, Reyes-Leyva J and Vallejo-Ruiz V: Enhanced sialyltransferases transcription in cervical intraepithelial neoplasia. Invest Clin 50: 45-53, 2009.
14. López-Morales D, Reyes-Leyva J, Santos-López G, Zenteno E and Vallejo-Ruiz V: Increased expression of sialic acid in cervical biopsies with squamous intraepithelial lesions. Diagn Pathol 5: 74, 2010.

15. Roy A and Chakraborty S: Detection of cancer cervix by estimation of sialic acid. J Indian Med Assoc 103: 589-590, 2005.

16. Terasawa K, Furumoto H, Kamada M and Aono T: Expression of Tn and sialyl-Tn antigens in the neoplastic transformation of uterine cervical epithelial cells. Cancer Res 56: 2229-2232, 1996.

17. Engelstaedter V, Fluegel B, Kunze S, Mayr D, Friese K, Jeschke U and Bergauer F: Expression of the carbohydrate tumour marker Sialyl Lewis A, Sialyl Lewis X, Lewis Y and Thomsen-Friedenreich antigen in normal squamous epithelium of the uterine cervix, cervical dysplasia and cervical cancer. Histol Histopathol 27: 507-514, 2012.

18. Velázquez-Márquez N, Santos-López G, Jiménez-Aranda L, Reyes-Leyva $\mathbf{J}$ and Vallejo-Ruiz V: Sialyl Lewis $\mathrm{x}$ expression in cervical scrapes of premalignant lesions. J Biosci 37: 999-1004, 2012.

19. Aco-Tlachi M, Carreño-López R, Martínez-Morales PL, Maycotte P, Aguilar-Lemarroy A, Jave-Suárez LF, Santos-López G, Reyes-Leyva J and Vallejo-Ruiz V: Glycogene expression profiles based on microarray data from cervical carcinoma HeLa cells with partially silenced E6 and E7 HPV oncogenes. Infect Agent Cancer 13: 25, 2018.

20. Kabsch K and Alonso A: The human papillomavirus type 16 E5 protein impairs TRAIL- and FasL-mediated apoptosis in HaCaT cells by different mechanisms. J Virol 76: 12162-12172, 2002.

21. Buettner FF, Ashikov A, Tiemann B, Lehle L and Bakker H: C. elegans DPY-19 is a C-mannosyltransferase glycosylating thrombospondin repeats. Mol Cell 50: 295-302, 2013.

22. Milde-Langosch K, Karn T, Schmidt M, zu Eulenburg C, Oliveira-Ferrer L, Wirtz RM, Schumacher U, Witzel I, Schütze D and Müller V: Prognostic relevance of glycosylation-associated genes in breast cancer. Breast Cancer Res Treat 145: 295-305, 2014.

23. Recchi MA, Hebbar M, Hornez L, Harduin-Lepers A, Peyrat JP and Delannoy P: Multiplex reverse transcription polymerase chain reaction assessment of sialyltransferase expression in human breast cancer. Cancer Res 58: 4066-4070, 1998.

24. Jin XL, Zheng SS, Wang BS and Chen HL: Correlation of glycosyltransferases mRNA expression in extrahepatic bile duct carcinoma with clinical pathological characteristics. Hepatobiliary Pancreat Dis Int 3: 292-295, 2004.

25. Petretti T, Kemmner W, Schulze B and Schlag PM: Altered mRNA expression of glycosyltransferases in human colorectal carcinomas and liver metastases. Gut 46: 359-366, 2000.

26. Ashkani J and Naidoo KJ: Glycosyltransferase gene expression profiles classify cancer types and propose prognostic subtypes. Sci Rep 6: 26451, 2016.

27. Gretschel S, Haensch W, Schlag PM and Kemmner W: Clinical relevance of sialyltransferases ST6GAL-I and ST3GAL-III in gastric cancer. Oncology 65: 139-145, 2003.

28. Zhang S, Lu J, Xu Z, Zou X, Sun X, Xu Y, Shan A, Lu J, Yan X, Cui Y, et al: Differential expression of ST6GAL1 in the tumor progression of colorectal cancer. Biochem Biophys Res Commun 486: 1090-1096, 2017.

29. Swindall AF, Londoño-Joshi AI, Schultz MJ, Fineberg N, Buchsbaum DJ and Bellis SL: ST6Gal-I protein expression is upregulated in human epithelial tumors and correlates with stem cell markers in normal tissues and colon cancer cell lines. Cancer Res 73: 2368-2378, 2013.

30. Schultz MJ, Holdbrooks AT, Chakraborty A, Grizzle WE, Landen CN, Buchsbaum DJ, Conner MG, Arend RC, Yoon KJ, Klug CA, et al: The tumor-associated glycosyltransferase ST6Gal-I regulates stem cell transcription factors and confers a cancer stem cell phenotype. Cancer Res 76: 3978-3988, 2016.

31. Vázquez-Martín C, Gil-Martín E and Fernández-Briera A: Elevation of ST6Gal I activity in malignant and transitional tissue in human colorectal cancer. Oncology 69: 436-444, 2005.

32. Chakraborty A, Dorsett KA, Trummell HQ, Yang ES, Oliver PG, Bonner JA, Buchsbaum DJ and Bellis SL: ST6Gal-I sialyltransferase promotes chemoresistance in pancreatic ductal adenocarcinoma by abrogating gemcitabine-mediated DNA damage. J Biol Chem 293: 984-994, 2018.

33. Potapenko IO, Haakensen VD, Lüders T, Helland A, Bukholm I, Sørlie T, Kristensen VN, Lingjaerde OC and Børresen-Dale AL: Glycan gene expression signatures in normal and malignant breast tissue; possible role in diagnosis and progression. Mol Oncol 4: 98-118, 2010 
34. Chen X, Yang TT, Qiu XC, Ji ZG, Li CX, Long H, Zhou Y, Ma BA, Ma Q, Zhang X, et al: Gene expression profiles of human osteosarcoma cell sublines with different pulmonary metastatic potentials. Cancer Biol Ther 11: 287-292, 2011.

35. Warnecke-Eberz U, Metzger R, Hölscher AH, Drebber U and Bollschweiler E: Diagnostic marker signature for esophageal cancer from transcriptome analysis. Tumour Biol 37: 6349-6358, 2016.

36. Seko A, Kataoka F, Aoki D, Sakamoto M, Nakamura T, Hatae M, Yonezawa S and Yamashita K: N-Acetylglucosamine 6-O-sulfotransferase-2 as a tumor marker for uterine cervical and corpus cancer. Glycoconj J 26: 1065-1073, 2009.

37. Sud N, Sharma R, Ray R, Chattopadhyay T and Ralhan R: Differential expression of beta mannosidase in human esophageal cancer. Int J Cancer 112: 905-907, 2004.

38. Pfeiffer MJ, Smit FP, Sedelaar JP and Schalken JA: Steroidogenic enzymes and stem cell markers are upregulated during androgen deprivation in prostate cancer. Mol Med 17: 657-664, 2011.

39. Chen X, Li D, Wang N, Yang M, Liao A, Wang S, Hu G, Zeng B, Yao Y, Liu D, et al: Bioinformatic analysis suggests that UGT2B15 activates the Hippo YAP signaling pathway leading to the pathogenesis of gastric cancer. Oncol Rep 40: 1855-1862, 2018.

40. Pâquet S, Fazli L, Grosse L, Verreault M, Têtu B, Rennie PS Bélanger $\mathrm{A}$ and Barbier O: Differential expression of the androgen-conjugating UGT2B15 and UGT2B17 enzymes in prostate tumor cells during cancer progression. J Clin Endocrino Metab 97: E428-E432, 2012.

41. Libisch MG, Casás M, Chiribao M, Moreno P, Cayota A, Osinaga E, Oppezzo P and Robello C: GALNT11 as a new molecular marker in chronic lymphocytic leukemia. Gene 533: 270-279, 2014

42. Tátrai P, Egedi K, Somorácz A, van Kuppevelt TH, Ten Dam G, Lyon M, Deakin JA, Kiss A, Schaff Z and Kovalszky I: Quantitative and qualitative alterations of heparan sulfate in fibrogenic liver diseases and hepatocellular cancer. J Histochem Cytochem 58: 429-441, 2010.

43. Ushakov VS, Tsidulko AY, de La Bourdonnaye G, Kazanskaya GM, Volkov AM, Kiselev RS, Kobozev VV, Kostromskaya DV, Gaytan AS, Krivoshapkin AL, et al: Heparan sulfate biosynthetic system is inhibited in human glioma due to EXT1/2 and HS6ST1/2 D down-regulation. Int J Mol Sci 18: E2301, 2017.

44. Cengiz B, Yumrutas O, Bozgeyik E, Borazan E, Igci YZ, Bozgeyik I and Oztuzcu S: Differential expression of the UGT1A family of genes in stomach cancer tissues. Tumour Biol 36 $5831-5837,2015$

45. Starlard-Davenport A, Lyn-Cook B and Radominska-Pandya A: Identification of UDP-glucuronosyltransferase 1A10 in non-malignant and malignant human breast tissues. Steroids 73 611-620, 2008

46. Pinho SS and Reis CA: Glycosylation in cancer: Mechanisms and clinical implications. Nat Rev Cancer 15: 540-555, 2015.

47. Magalhães A, Duarte HO and Reis CA: Aberrant glycosylation in cancer: A novel molecular mechanism controlling metastasis. Cancer Cell 31: 733-735, 2017.

48. Harduin-Lepers A, Krzewinski-Recchi MA, Colomb F, FoulquierF, Groux-Degroote $S$ and Delannoy P: Sialyltransferases functions in cancers. Front Biosci (Elite Ed) 4: 499-515, 2012.
49. Estêvão D, Costa NR, Gil da Costa RM and Medeiros R Hallmarks of HPV carcinogenesis: The role of E6, E7 and E5 oncoproteins in cellular malignancy. Biochim Biophys Acta Gene Regul Mech 1862: 153-162, 2019.

50. Oetke C, Auvinen E, Pawlita M and Alonso A: Human papillomavirus type 16 E5 protein localizes to the Golgi apparatus but does not grossly affect cellular glycosylation. Arch Virol 145: 2183-2191, 2000

51. VandammeV,Pierce A, Verbert A and Delannoy P:Transcriptional induction of beta-galactoside alpha-2,6-sialyltransferase in rat fibroblast by dexamethasone. Eur J Biochem 211: 135-140, 1993.

52. Coughlan CM, Burger PG, Berger EG and Breen KC: The biochemical consequences of alpha2,6(N) sialyltransferase induction by dexamethasone on sialoglycoprotein expression in the rat H41le hepatoma cell line. FEBS Lett 413: 389-393, 1997.

53. Caterson B and Melrose J: Keratan sulfate, a complex glycosaminoglycan with unique functional capability. Glycobiology 28 : 182-206, 2018.

54. D'Angelo G, Capasso S, Sticco L and Russo D: Glycosphingolipids: Synthesis and functions. FEBS J 280: 6338-6353, 2013.

55. Zhuo D, Li X and Guan F: Biological roles of aberrantly expressed glycosphingolipids and related enzymes in human cancer development and progression. Front Physiol 9: 466, 2018.

56. Suprynowicz FA, Disbrow GL, Krawczyk E, Simic V, Lantzky K and Schlegel R: HPV-16 E5 oncoprotein upregulates lipid raft components caveolin-1 and ganglioside GM1 at the plasma membrane of cervical cells. Oncogene 27: 1071-1078, 2008.

57. Harduin-Lepers A, Vallejo-Ruiz V, Krzewinski-Recchi MA, Samyn-Petit B, Julien S and Delannoy P: The human sialyltransferase family. Biochimie 83: 727-737, 2001.

58. Ohmori K, Kanda K, Mitsuoka C, Kanamori A, Kurata-Miura K, Sasaki K, Nishi T, Tamatani T and Kannagi R: P- and E-selectins recognize sialyl 6-sulfo Lewis $X$, the recently identified L-selectin ligand. Biochem Biophys Res Commun 278: 90-96, 2000.

59. Lu J and Gu J: Significance of $\beta$-galactoside $\alpha 2,6$ sialyltranferase 1 in cancers. Molecules 20: 7509-7527, 2015.

60. Seales EC, Jurado GA, Brunson BA, Wakefield JK, Frost AR and Bellis SL: Hypersialylation of betal integrins, observed in colon adenocarcinoma, may contribute to cancer progression by up-regulating cell motility. Cancer Res 65: 4645-4652, 2005.

61. Park JJ, Yi JY, Jin YB, Lee YJ, Lee JS, Lee YS, Ko YG and Lee M: Sialylation of epidermal growth factor receptor regulates receptor activity and chemosensitivity to gefitinib in colon cancer cells. Biochem Pharmacol 83: 849-857, 2012.

62. Tomakidi P, Cheng H, Kohl A, Komposch G and Alonso A: Modulation of the epidermal growth factor receptor by the human papillomavirus type $16 \mathrm{E} 5$ protein in raft cultures of human keratinocytes. Eur J Cell Biol 79: 407-412, 2000.

63. Deligny A, Dierker T, Dagälv A, Lundequist A, Eriksson I, Nairn AV, Moremen KW, Merry CLR and Kjellén L: NDST2 (N-Deacetylase/N-Sulfotransferase-2) enzyme regulates heparan sulfate chain length. J Biol Chem 291: 18600-18607, 2016.

This work is licensed under a Creative Commons Attribution-NonCommercial-NoDerivatives 4.0 International (CC BY-NC-ND 4.0) License. 